\title{
Analysis of a rapid sea ice retreat event in the Bellingshausen Sea
}

\author{
J. C. King, ${ }^{1}$ M. J. Doble, ${ }^{2,3}$ and P. R. Holland ${ }^{1}$ \\ Received 6 January 2010; revised 8 July 2010; accepted 20 September 2010; published 15 December 2010.
}

[1] The winter advance of the sea ice edge in the Bellingshausen Sea is frequently interrupted by periods of rapid retreat lasting a few days. The frequency and duration of such events strongly controls the location of the late winter sea ice edge in this sector of the Antarctic. We examine the dynamics and thermodynamics of a retreat event that occurred in May 2001 using data from a drifting buoy array together with diagnostics from a kinematic/thermodynamic ice growth model and a high-resolution $(11 \mathrm{~km})$ regional coupled ocean-ice model. During the retreat event, the ice edge retreated by $250 \mathrm{~km}$ over 13 days in response to strong and persistent northerly winds associated with a quasi-stationary low-pressure system. Ice motion in the outer part of the pack was convergent and correlated strongly with local wind forcing. By contrast, in the region closer to the coast, ice motion was less well correlated with wind forcing. Model diagnostics indicate that ice thickening resulting from convergence in the outer pack was largely balanced by basal melting. In the outer pack, ice was in a state close to free drift while, closer to the coast, internal ice stresses became significant. The ocean-ice model simulated the characteristics of the retreat event realistically, giving us confidence in the ability of such models to reproduce ice conditions in this sector.

Citation: King, J. C., M. J. Doble, and P. R. Holland (2010), Analysis of a rapid sea ice retreat event in the Bellingshausen Sea, J. Geophys. Res., 115, C12030, doi:10.1029/2010JC006101.

\section{Introduction}

[2] Over the past 50 years, the west coast of the Antarctic Peninsula has warmed more rapidly than any other region on Earth [Turner et al., 2005]. Most of this warming has occurred during winter, a season when Antarctic Peninsula temperatures are very sensitive to sea ice extent in the Bellingshausen Sea immediately to the west of the Peninsula [King, 1994]. There are indications that the duration of the sea ice season in this sector has reduced significantly in recent years [Zwally et al., 2002] and that winter sea ice production has declined [Meredith and King, 2005]. It is highly likely that the rapid warming of the peninsula west coast in winter has been largely driven by changes in sea ice cover in the Bellingshausen Sea which, in turn, probably reflect changes in atmospheric circulation [Turner et al., 2009]. The modeling study of Holland et al. [2010] suggests that variability in sea ice extent also affects the properties of water masses on-shelf in the Bellingshausen Sea, thereby controlling the basal melting of collapsing ice shelves in the region.

[3] The factors controlling Bellingshausen Sea ice extent are not fully understood. The development of the winter sea

\footnotetext{
${ }^{1}$ British Antarctic Survey, Cambridge, UK.

${ }^{2}$ Department of Applied Mathematics and Theoretical Physics, University of Cambridge, UK.

${ }^{3}$ Currently at Laboratoire d'Océanographie de Villefranche, UPMC Univ Paris 06, Villefranche/mer, France.

Copyright 2010 by the American Geophysical Union. 0148-0227/10/2010JC006101
}

ice cover in this sector is characterized by alternating periods of ice advance and retreat in response to changed atmospheric forcing associated with the passage of synoptic scale weather systems. Harangozo [1997, 2004] demonstrated that variability in the final winter ice extent depends strongly on the frequency and duration of retreat episodes, with the total advance showing less variation from year to year. Investigating the dynamics of ice retreat episodes is thus a crucial part of understanding climate variability and change in this region.

[4] There have been several studies of ice retreat events in the Bellingshausen Sea. Turner et al. [2003] used satellite observations and numerical weather prediction data to investigate a $400 \mathrm{~km}$ retreat of the ice edge around $80^{\circ} \mathrm{W}$ over 2 weeks in August 1993. Massom et al. [2006] reported a $300 \mathrm{~km}$ ice edge retreat at $70^{\circ} \mathrm{W}$ and associated rapid compaction and thickening of the ice cover over 19 days during the late austral winter of 2001 in response to anomalous northerly winds over the Bellingshausen Sea. Similar atmospheric anomalies during the late winter of 2005 also gave rise to anomalous ice retreat and compaction in this sector [Massom et al., 2008].

[5] A weakness of these previous studies is that no in situ observations of ice motion were available to enable a full investigation of ice dynamics to be made. While estimates of sea ice motion can be made from passive microwave satellite imagery [e.g., Emery et al., 1997], the spatial and temporal resolution of such products is generally inadequate for studying the dynamics of Bellingshausen Sea ice retreat events, which occur over a period of a few days with a 
spatial scale of a few hundreds of kilometers. In this paper, we examine a rapid retreat event that took place during the late austral autumn of 2001, where ice motion was well characterized by observations from drifting buoys. We use the buoy drift data together with satellite observations of ice concentration, atmospheric data from numerical weather prediction models, and diagnostics from a kinematic-thermodynamic ice growth model and a full sea ice-ocean model to determine the factors that forced the ice retreat. We conclude by discussing the climatological significance of our findings.

\section{Data Sources}

[6] We focus on an ice retreat event that took place in the southern Bellingshausen Sea between 2 and 15 May 2001. Information on ice drift during this event was available from four drifting platforms that were deployed during a cruise of the research vessel Polarstern in April 2001. A MetOcean Compact Air-Launched Ice Buoy (CALIB) was deployed directly from the ship onto a first year ice floe (thickness, $60-80 \mathrm{~cm}, 5 \mathrm{~cm}$ snow cover, $100 \%$ ice concentration) at $71^{\circ} \mathrm{S}, 85^{\circ} \mathrm{W}$ on 23 April. On 25 April, three MetOcean Surface Velocity Profiling Barometers (SVPBs) were deployed using the ship's helicopters onto consolidated pancake ice (approximately $20 \mathrm{~cm}$ thick with $5 \mathrm{~cm}$ of snow cover, $80 \%$ ice concentration) between $69^{\circ} \mathrm{S}$ and $70^{\circ} \mathrm{S}$ and between $85^{\circ} \mathrm{W}$ and $89^{\circ} \mathrm{W}$. One SVPB ceased transmissions on 14 May and the CALIB failed on 21 May. The longestlived of the remaining two SVPBs finally ceased transmitting on 1 October. Both the SVPBs and the CALIB measured atmospheric pressure and reported this, together with their position determined to an accuracy of about $500 \mathrm{~m}$, through the ARGOS data collection system. Typically 20 position reports per day were available from each platform. Pressure data from the SVPBs were made available on the World Meteorological Organisation's Global Telecommunications System (GTS).

[7] Sea ice concentration data were obtained from the National Snow and Ice Data Center (NSIDC). We have used ice concentration fields derived from passive microwave satellite observations processed using the Bootstrap algorithm [Comiso, 1999]. These data are available at daily intervals on a polar stereographic grid with a pixel size of approximately $25 \mathrm{~km} \times 25 \mathrm{~km}$. For comparison, we recomputed some of the results of this study using ice concentrations derived from the NASA Team algorithm. The two ice products are in good agreement for the event studied in this paper and use of the alternative ice data set did not affect any of our conclusions.

[8] Fields of mean sea level pressure, air temperature at $2 \mathrm{~m}$ and wind components at $10 \mathrm{~m}$ were extracted from 6 hourly operational analyses prepared by the European Centre for Medium Range Weather Forecasts (ECMWF). The ECMWF forecast system used a global spectral model that, in early 2001, was run at a triangular truncation of TL511, equivalent to approximately $40 \mathrm{~km}$ horizontal resolution. The ECMWF data used in this study were supplied on a $1.125^{\circ} \times 1.125^{\circ}$ latitude-longitude grid. King [2003] has shown that these analyses provide a good description of atmospheric conditions over the southern Bellingshausen Sea in spite of the lack of in situ meteorological observations from this sector.
[9] Two models were used to help interpret the observations. The kinematic/thermodynamic model of Doble et al. [2003] was used to estimate changes in ice thickness within the area enclosed by the SVPBs and gain insight into its sensitivity to forcing parameters. The model couples the observed buoy motions (differential kinematic parameters) with a one-dimensional energy balance model, forced using surface fluxes calculated from ECMWF analysis data at the buoy locations, using a range of prescribed values for the ocean-ice heat flux. The buoy kinematics and modeled ice growth/melt are used to determine the thickness of a number of ice classes (six in this model), tracking each mean class thickness and area as the ice cover evolves.

[10] Information on the broader-scale features of sea-ice behavior were obtained from a coupled system [Holland et al., 2010] based on the three-dimensional Miami IsopycnicCoordinate Ocean Model (MICOM) [Bleck et al., 1992] and the Los Alamos CICE sea ice model [Hunke and Lipscomb, 2006] forced by atmospheric reanalyses. The model components exchange fluxes of heat, salt, mass, and momentum on an hourly coupling time step. The MICOM ocean comprises a stack of isopycnic layers beneath a surface mixed layer that has a freely evolving density. The mixed layer handles interaction with the overlying atmosphere or ice and communicates with the interior ocean layers via an entrainment/detrainment routine. CICE divides the ice into five thickness categories and features elastic-viscous-plastic ice dynamics, the energybased mechanical redistribution (ridging and rafting) scheme of Thorndike et al. [1975], and an ice strength parameterization given by Rothrock [1975]. The energy-conserving thermodynamics model divides each thickness category into five thermodynamic layers of which the uppermost is snow. The ocean-ice heat flux is parameterized according to the formula of Maykut and McPhee [1995].

[11] Ocean variables were relaxed to atlas values at the open ocean boundaries [Olbers et al., 1992]. For historical reasons, surface forcing was taken from the National Centers for Environmental Prediction (NCEP) reanalysis rather than the ECMWF product. However, comparison of the two products shows insignificant differences in the forcing variables over the study area during May 2001. Apart from using a $0.3^{\circ}$ (approximately $11 \mathrm{~km}$ ) grid and outputting 6 hourly data over a shorter simulation period (1999-2002), the model implementation was identical to that used in the study of Holland et al. [2010], which showed good agreement with sea ice observations in a multidecadal simulation of the Bellingshausen Sea.

\section{Results}

\subsection{Observations}

[12] The autumn and early winter of 2001 were characterized by the development of deep and slow-moving lowpressure systems over the Amundsen and Bellingshausen seas. On 2 May, one such low-pressure system lay at around $135^{\circ} \mathrm{W}$, bringing northerly winds to the study area (Figure 1a). Over the following 3 days, this low remained fairly stationary and deepened slightly. From 7 May, the east-west pressure gradient to the east of the low center increased as a ridge of high pressure developed and persisted across the Antarctic Peninsula and western Weddell Sea (Figure 1b). The pressure gradient reached a maximum on 14 May (Figure 1c), after 

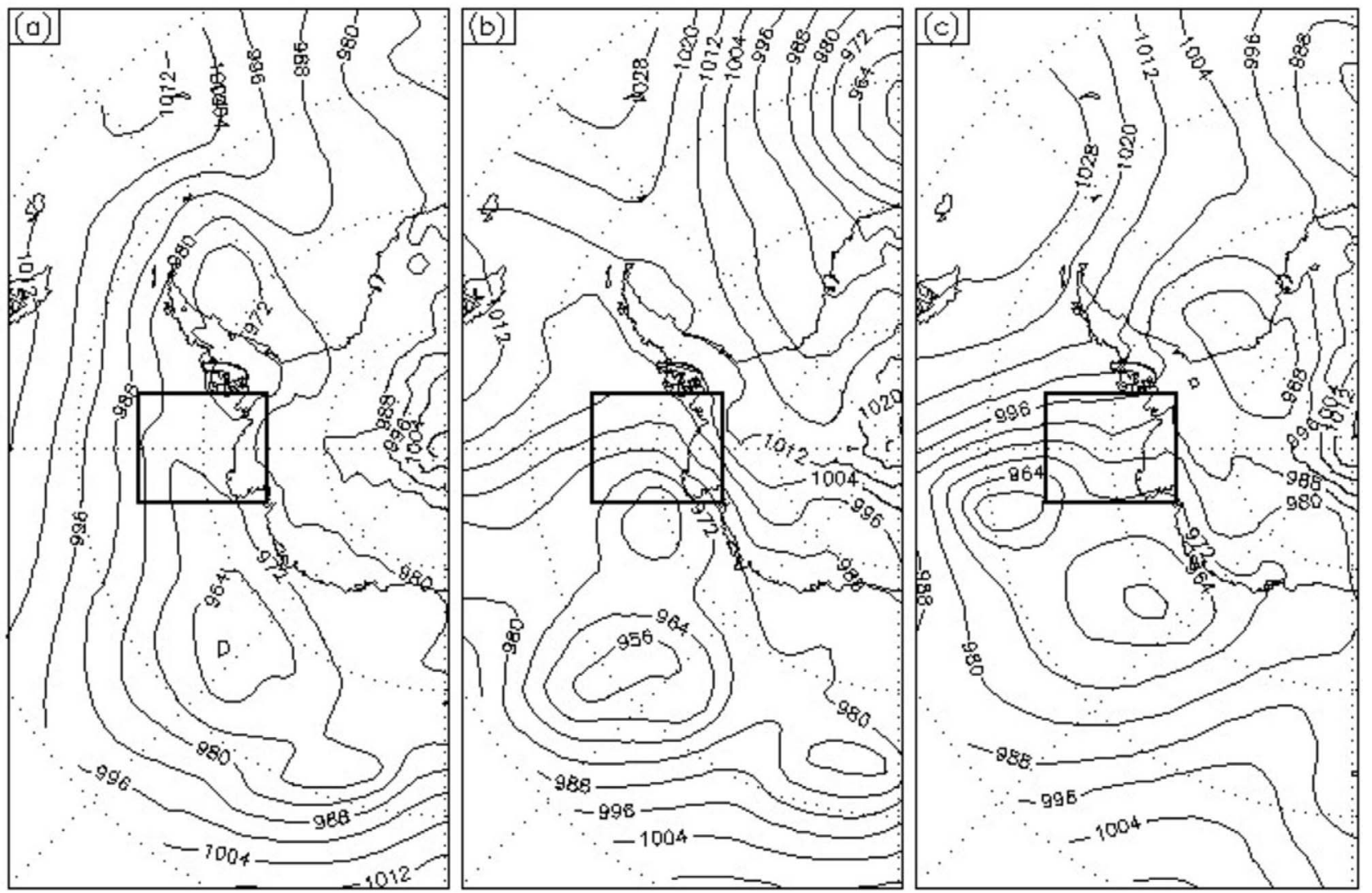

Figure 1. ECMWF mslp analyses at 0000 UTC on (a) 2 May 2001, (b) 7 May 2001, and (c) 14 May 2001. The study region (area of Figure 2) is outlined with a heavy line.

which the low-pressure center drifted northward and eastward into the Drake Passage, leaving the study area under the influence of weak easterly winds.

[13] In response to these strong and persistent northerly winds, the sea ice edge between $80^{\circ} \mathrm{W}$ and $90^{\circ} \mathrm{W}$ retreated rapidly over a 2 week period. Figure 2 shows the ice concentration at the start and end of the retreat event, together with daily positions of the four drifting buoys. Between 2 and 15 May, the ice edge between $85^{\circ} \mathrm{W}$ and $90^{\circ} \mathrm{W}$ retreated by $250 \mathrm{~km}$. The SVPBs, which were between 100 and $150 \mathrm{~km}$ south of the ice edge at the start of the retreat event, moved $220 \mathrm{~km}$ southward with little drift in the zonal direction. By contrast, the CALIB, initially positioned $310 \mathrm{~km}$ south of the ice edge, moved only $90 \mathrm{~km}$ southward but also drifted $100 \mathrm{~km}$ westward.

[14] Table 1 illustrates the relationships between observed daily mean ice drift velocities and winds at $10 \mathrm{~m}$ from the ECMWF analyses. SVPB drift speeds were well correlated with variations in wind speed. The ratio of ice drift to wind speed was close to that measured in the central Weddell Sea [Vihma et al., 1996] and around East Antarctica [Heil et al., 2009] but was somewhat lower than the value measured for recently consolidated pancake ice in the Weddell Sea by Doble and Wadhams [2006]. The mean ratio of ice drift to wind speed changed little when ice drift was computed over $6 \mathrm{~h}$, rather than $24 \mathrm{~h}$, intervals but the correlation coefficient between ice drift and wind speed reduced from 0.92 to 0.75 . The decorrelation is probably a result of semidiurnal ice motions (described below) that are uncorrelated with wind forcing being resolved in the $6 \mathrm{~h}$ analysis. Winds at the more southerly CALIB location were slightly weaker and had more of an easterly component, probably as a result of blocking of the northerly flow at low levels by the steep Antarctic coastal orography [Orr et al., 2004]. This change in wind forcing as the coast is approached will have contributed to the slower and more westward drift of the CALIB but, on its own, is not sufficient to account for all of the differences between the SVPB and CALIB drifts. The ratio of ice drift to wind speed for the CALIB is lower and more variable than that for the SVPBs and the correlation between variations in ice drift and in wind speed is much weaker. The weaker relationship between wind forcing and ice drift at the CALIB location could indicate that the representation of the wind field in the ECMWF analyses is poorer nearer the coast than over the open ocean. However, the reduced correlation coefficient and smaller ice drift/wind speed ratio also suggest that factors in addition to wind forcing, such as ocean currents and internal ice stresses, are important in controlling ice motion at the CALIB location.

[15] Power spectra of the meridional component of drift velocity of one of the SVPBs and the CALIB are displayed in Figure 3. Both buoys show a peak in spectral power at typical synoptic periods of 2-4 days. This peak is also visible in the spectra of wind forcing (not shown) and probably represents the effects of troughs and other minor systems moving around the quasi-stationary low. 

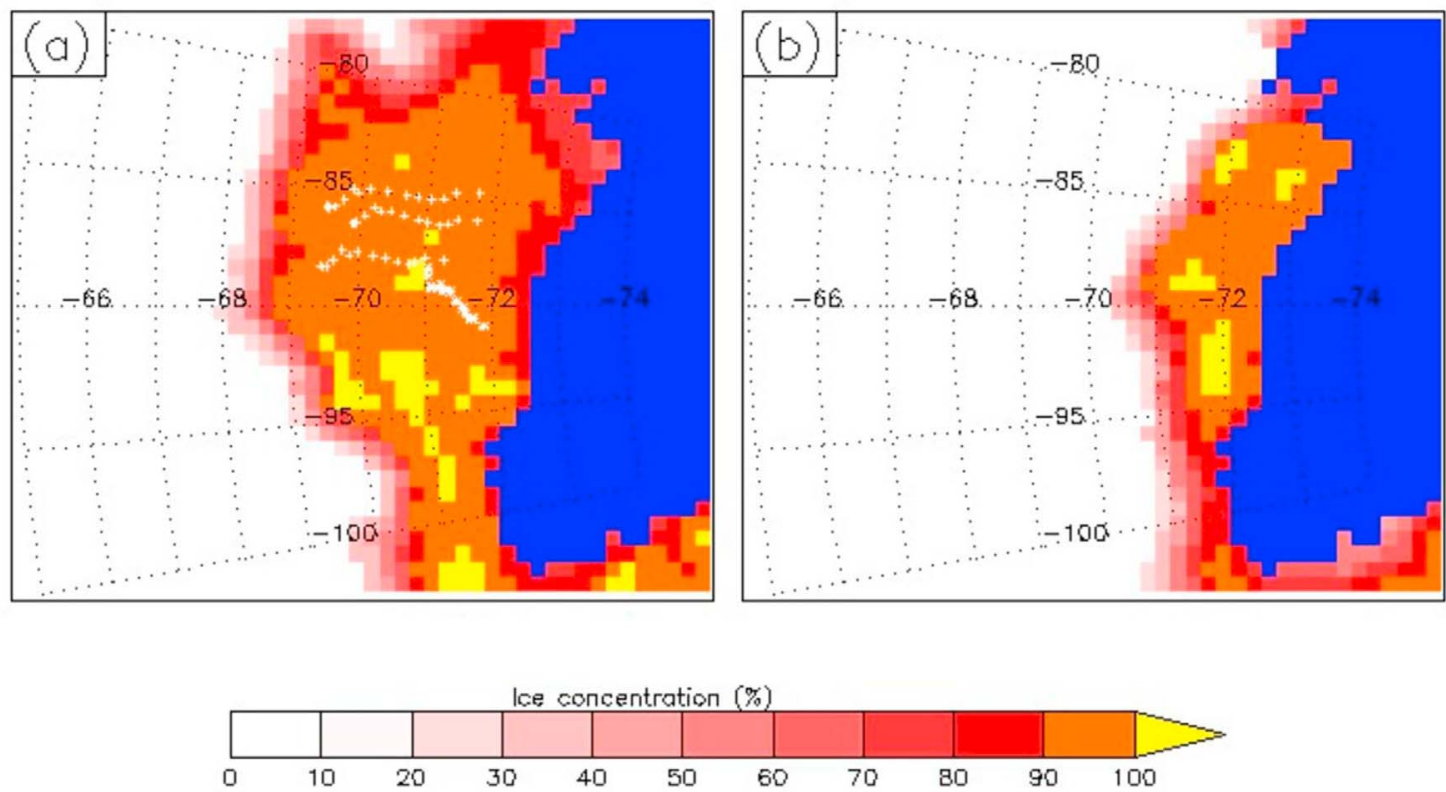

Figure 2. Ice concentration in the study area on (a) 2 May 2001 and (b) 15 May 2001. Also shown on Figure 2a are the daily (0000 UTC) positions of the three SVPBs (white crosses) and the CALIB (white asterisks).

Additionally, both buoys show a peak at around two cycles per day (cpd) that is statistically significant at the $1 \%$ level when tested against a fitted red noise spectrum. Rotary spectra were used to separate the effects of inertial motion $\left(1.88 \mathrm{cpd}\right.$ at $\left.70^{\circ} \mathrm{S}\right)$ and forcing by the lunar semidiurnal tide (M2, $1.93 \mathrm{cpd}$ ) [Emery and Thompson, 1998]. Results suggest that the semidiurnal motions are inertial rather than tidal, since the peak appears in the counterclockwise spectrum only. The power at the semidiurnal peak for the CALIB is only approximately one third of that for the SVPB, suggesting that ice stresses are of greater relative importance in the coastal region.

[16] Between 2 and 15 May, the retreat of the ice edge between $80^{\circ} \mathrm{W}$ and $90^{\circ} \mathrm{W}$ led to a reduction of $1.2 \times 10^{5} \mathrm{~km}^{2}$ of ice extent in this sector. Since the ice concentration within the sector was high at the start of the event, there was little scope for ice compaction to contribute to the retreat. Indeed, the decrease in ice area within the sector $\left(1.1 \times 10^{5} \mathrm{~km}^{2}\right)$ differed little from the decrease in extent. In the absence of significant compaction, the retreat of the ice edge must have been balanced by surface or basal ice melting, by thickening as a result of ridging and/or rafting driven by ice convergence, by advection of ice out of the sector, or by a combination of these factors. Since the buoys that we deployed did not measure wind speed or atmospheric or ocean temperatures, we were not able to calculate melt rates directly. Estimates of surface and basal melt rates are available from the ocean-ice model simulations discussed below. For the present, we note that $2 \mathrm{~m}$ atmospheric temperatures in the study area taken from the ECMWF analyses never rose above $1^{\circ} \mathrm{C}$, so surface melting is likely to have been small, while basal melt rates associated with modeled ocean heat fluxes were of order $1 \mathrm{~cm} \mathrm{~d}^{-1}$.

[17] In order to investigate the contributions of convergence and advection to the ice retreat, we have calculated time series of the areas of triangles formed by groups of three buoys. Figure 4 shows the evolution of the area of the triangle formed by the three SVPBs (representative of conditions in the outer part of the ice pack) and of that formed by the outer two SVPBs and the CALIB (representative of broader-scale conditions over the sea ice in this sector). In this figure, the triangle areas are scaled by the area at the start of the event (1200 UTC on 2 May 2001). Also shown is the estimated ice-covered area within each triangle, calculated by multiplying the triangle area by the mean ice concentration from pixels within the triangle. As ice concentrations were high to start with and remained high throughout the retreat event the differences between

Table 1. Means ( \pm One Standard Deviation) over 2-15 May 2001 of $10 \mathrm{~m}$ Wind Speed and Direction $\left(\left\langle V_{\text {wind }}\right\rangle\right.$, $\left.\left\langle\theta_{\text {wind }}\right\rangle\right)$ Ice Drift Speed and Direction $\left(\left\langle V_{\text {ice }}\right\rangle,\left\langle\theta_{\text {ice }}\right\rangle\right)$, the Ratio of Ice Drift Speed to Wind Speed, and the Correlation Coefficient (cc) Between Ice Drift Speed and Wind Speed at the Locations of the Drifting Buoys ${ }^{\mathrm{a}}$

\begin{tabular}{lccccc}
\hline & $\left\langle V_{\text {wind }}\right\rangle\left(\mathrm{m} \mathrm{s}^{-1}\right)$ & $\left\langle V_{\text {ice }}\right\rangle\left(\mathrm{m} \mathrm{s}^{-1}\right)$ & $\left\langle\theta_{\text {wind }}\right\rangle\left(^{\circ}\right)$ & $\left\langle\theta_{\text {ice }}\right\rangle\left(^{\circ}\right)$ & $\left\langle V_{\text {ice }} / V_{\text {wind }}\right\rangle$ \\
\hline SVPBs & $9.1 \pm 3$ & $0.21 \pm 0.09$ & $15 \pm 20$ & $175 \pm 25$ & $0.023 \pm 0.004$ \\
CALIB & $8.8 \pm 2.6$ & $0.14 \pm 0.06$ & $37 \pm 31$ & $220 \pm 39$ & $0.018 \pm 0.01$ \\
\hline
\end{tabular}

${ }^{a}$ Daily mean ice drift velocities were calculated from time series of buoy locations interpolated to 0000 UTC. Daily $10 \mathrm{~m}$ wind velocities were calculated by averaging the ECMWF analyses for 0000, 0600, 1200, and 1800 UTC and then spatially interpolating the averaged wind data to the buoy location interpolated to 1200 UTC. 


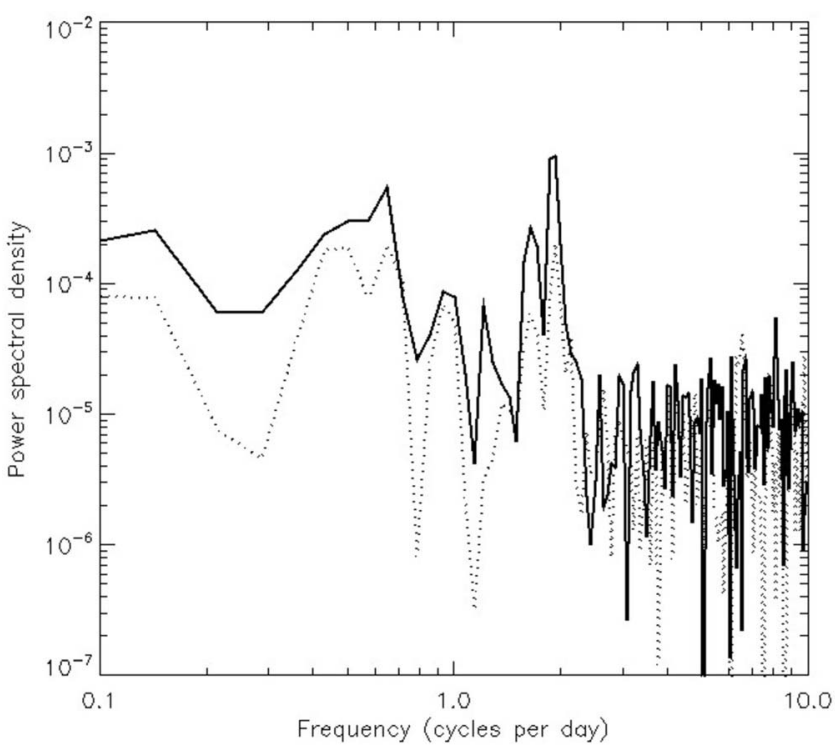

Figure 3. Power spectra of the meridional component of ice drift velocity from one of the SVPBs (solid line) and the CALIB (dotted line).

total triangle area and ice-covered area are small, confirming that compaction did not contribute significantly to changes in triangle area. Changes in triangle area, therefore, directly reflect the dynamical contribution to changes in ice thickness.

[18] The smaller triangle, formed by the three SVPBs, decreased to about $55 \%$ of its initial area over the period of the retreat event, indicating significant ice convergence and consequent dynamical thickening of ice in the outer part of the pack. Assuming an initial ice thickness of $0.2 \mathrm{~m}$, this convergence equates to a thickening rate of about $9.5 \mathrm{~m}$ $\mathrm{yr}^{-1}$. By contrast, the larger triangle formed by the two outer SVPBs and the CALIB, which is representative of broadscale conditions over the pack ice, only decreased to about $80 \%$ of its original area. Convergence over the smaller triangle was therefore above the mean over the larger, encom-

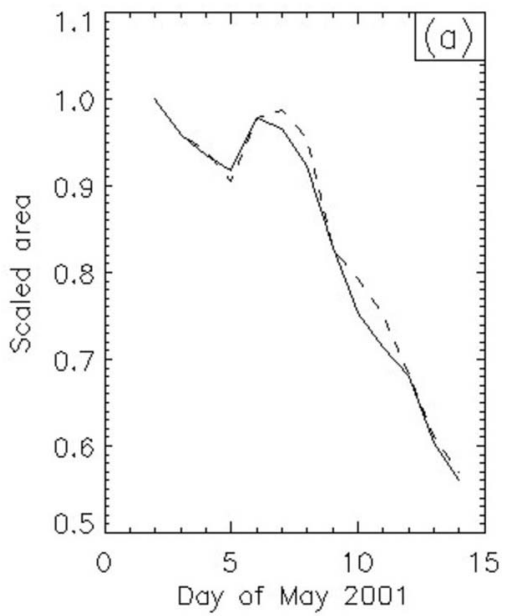

passing triangle, implying lower convergence in the remaining area near to the coast as a result of the increasingly westward movement of the ice as it approached the coast. The rapid southward flux of ice in the outer part of the pack ice was therefore largely balanced by westward advection of ice closer to the coast, leading to small overall convergence and relatively low dynamical thickening averaged over the larger triangle.

\subsection{Results From a Small-Scale Kinematic/ Thermodynamic Model}

[19] The kinematic/thermodynamic model of Doble et al. [2003] was used to assess the relative contributions of dynamical and thermodynamic processes to changes in ice thickness on the scale of the SVPB array. We have used a value of $28 \mathrm{~W} \mathrm{~m}^{-2}$ for the ocean-ice heat flux in the control run of the model, as suggested by nearby measurements [Martinson et al., 2008] and by the results of the ocean-ice model described below. The model simulation was started on 27 April (the day of the SVPB deployments) so that the ice thickness could be initialized with measurements made on that day. Model results (Figure 5) then show that thermodynamic ice growth only occurs in the first 2 days of the simulation, with low air temperatures $\left(-13.6^{\circ} \mathrm{C}\right)$ increasing ice thickness by $2 \mathrm{~cm}$ over the SVPB array area. Thereafter, mild atmospheric conditions $\left(-4^{\circ} \mathrm{C}<\mathrm{Ta}<1^{\circ}\right)$ reduce the vertical temperature gradient (and hence the heat flux) through the ice, so most of the basal heat flux becomes available to drive basal melting. Net ice volume loss at the end of the retreat period was approximately $1.5 \times 10^{8} \mathrm{~m}^{3}$ or around $15 \mathrm{~cm}$ basal melt over the area of the SVPB array. This melt offsets the ice thickness increase of around $54 \mathrm{~cm}$ driven by ice dynamics (prolonged convergence and rafting), resulting in a final average ice thickness within the array of $39 \mathrm{~cm}$. Results of the simulation are, however very sensitive to the choice of ocean-ice heat flux. Decreasing the heat flux by 10 and $20 \mathrm{~W} \mathrm{~m}^{-2}$ (again as suggested by nearby measurements [Martinson et al., 2008]) gives figures of $2 \mathrm{~cm}$ basal melt and $10 \mathrm{~cm}$ net growth, respectively, with

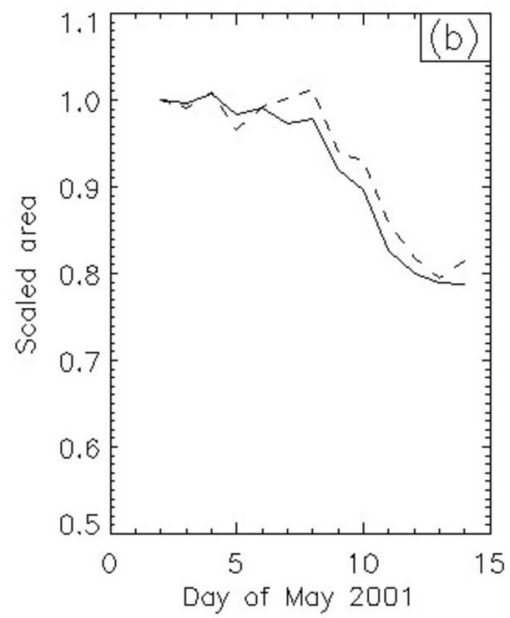

Figure 4. Time series of the areas of the triangles formed by (a) the three SVPBs and (b) the outer two SVPBs and the CALIB. The solid line shows the triangle area, while the broken line shows the icecovered area within the triangle. All areas have been scaled by their value at 1200 UTC on 2 May 2001. 

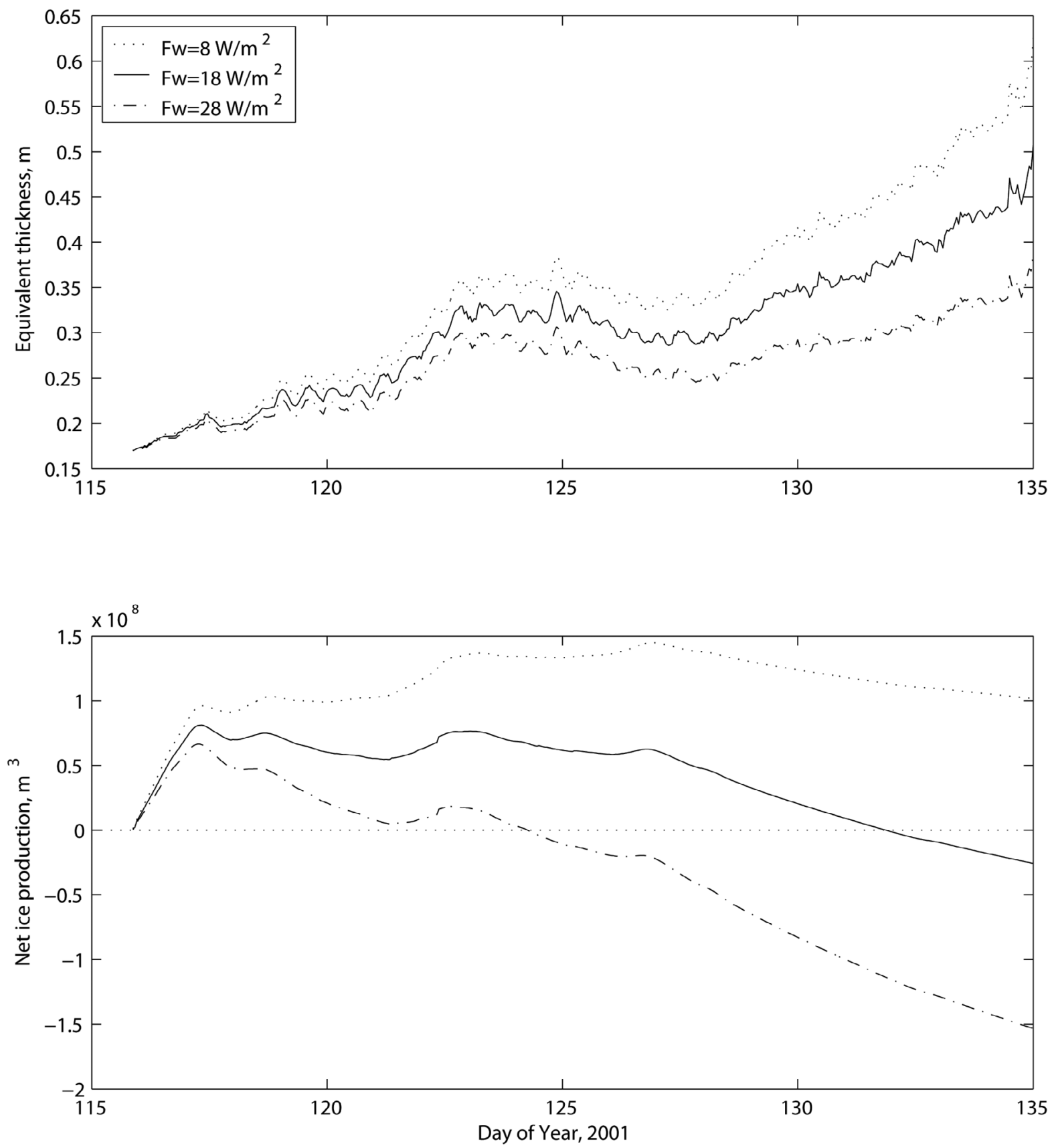

Figure 5. Results from the kinematic/thermodynamic model: (a) equivalent ice thickness and (b) total ice volume production. The solid lines show output from the model with an imposed ocean-ice heat flux of $18 \mathrm{~W} \mathrm{~m}^{-2}$, while the dashed and dotted lines show output from the model with this flux increased and decreased by $10 \mathrm{~W} \mathrm{~m}^{-2}$, respectively.

corresponding final ice thickness values within the array of 50 and $62 \mathrm{~cm}$. This sensitivity to imposed basal heat flux and the lack of observations with which to constrain this parameter have motivated us to run a more complex model that is capable of predicting the ocean forcing on the sea ice.

\subsection{Results From an Ocean-Ice Model}

[20] The ocean-ice model provides a larger-scale view of the processes that control the ice distribution. In the early autumn of 2001, the modeled ice edge expands northward due to thermodynamic growth, while ice nearer the coast is blown westward into the Amundsen Sea. Directly prior to retreat event, the observed ice extent was slightly underpredicted by the model (compare Figures $2 \mathrm{a}$ and $6 \mathrm{a}$ ). Over the period 3-22 May, the modeled ice edge in the $85^{\circ} \mathrm{W}-90^{\circ} \mathrm{W}$ sector retreated southward by around $150 \mathrm{~km}$ under the influence of northerly winds (Figures 6a-6c). The modeled retreat is somewhat smaller than the observed retreat $(250 \mathrm{~km})$, but some of this discrepancy may reflect the underprediction of the initial ice extent by the model. The magnitude and 
spatial distribution of modeled ice velocities in the middle of the retreat event (Figure 6b) matches the observations rather well. At the end of the retreat event, the remaining ice is again exported westward, before the winds change to southerlies, thermodynamic growth recommences, and the ice edge advances northward toward its winter maximum.

[21] The 10 May date is taken to be a representative time to analyze the midretreat behavior of the sea-ice model. In agreement with the data analysis above, the northerly wind removes ice from the outer pack and mechanically thickens ice closer to the coast (Figures $6 \mathrm{~d}$ and $6 \mathrm{e}$ ). There is a smaller but nonnegligible oceanic basal melting of ice in the eastern part of the study region that is apparently balanced by convergence (compare Figures 6e and 6f). In the region of the buoy measurements, the average basal heat flux is around $20 \mathrm{~W} \mathrm{~m}^{-2}$, which is close to the value used in the control run of the kinematic/thermodynamic model. Model diagnostics show that this relatively large heat flux is sustained in the absence of ice production (and consequent convective stirring of the mixed layer) by mechanical stirring induced by the stress imposed on the ocean by the rapidly retreating ice. No surface melting is predicted by the model.

[22] Figure 6e shows that ice is thinning dynamically everywhere except in a narrow region close to the coast. At first sight this appears inconsistent with the buoy observations, which show significant convergence (hence thickening) in the outer pack region (Figure $4 \mathrm{a}$ ). The reason for this apparent inconsistency is that the model results are presented in a fixed (Eulerian) frame of reference while the buoy network measures changes following the ice motion, i.e., in a Lagrangian framework. For ice at $100 \%$ concentration, of depth $h$ and drifting with velocity $u$, the Eulerian tendency equation for changes in ice thickness due to dynamical processes is

$$
\frac{\partial h}{\partial t}=-\nabla \cdot(h \underline{u})
$$

which expands to

$$
\frac{\partial h}{\partial t}+\underline{u} . \nabla h=-h \nabla \cdot \underline{u} .
$$

The term on the right hand side of (2) represents thickness changes resulting from convergence/divergence, which is what the buoy array measures, while the second term on the lefthand side is the contribution from advection. Using model data from 10 May for $90^{\circ} \mathrm{W}$ and $71^{\circ} \mathrm{S}-72^{\circ} \mathrm{S}$ and assuming that meridional derivatives dominate the gradient and divergence terms in (2), we calculate an advective thinning rate of about $11 \mathrm{~m} \mathrm{yr}^{-1}$ partially balanced by convergent thickening of about $8 \mathrm{~m} \mathrm{yr}^{-1}$. This latter figure agrees well with the convergent thickening of $9.5 \mathrm{~m} \mathrm{yr}^{-1}$ calculated from the SVPB array.

[23] The near-shore band of particularly rapid thickening in Figure 6e is focused in a narrow area because the mechanical redistribution scheme used in CICE preferentially selects thin ice for thickening. Thick ice resists redistribution so the northerly winds force the converging thin ice (which is at $100 \%$ concentration) to thicken in a band that approximately follows the $1 \mathrm{~m}$ ice thickness contour. The ice is transferred to thicker size classes in a manner designed to reproduce observed ice thickness distributions [Lipscomb et al., 2007], and this fundamentally determines both the position of the convergence and the maximum ice thickness near the coast. Owing to a lack of 2001 thickness data the parameters used are standard values from Arctic studies, but the thicknesses obtained are not unreasonable [Haas, 1998; Banks et al., 2006; Worby et al., 1996], particularly given the difficulty inherent in comparing model results with field observations.

[24] The model's prediction of the ratio of wind speed to ice speed (Figure 7a) shows good agreement with the observations (Table 1). In particular, the open-ocean ratio of around $2 \%$ decreases as the shoreline is approached. A closer analysis of the dominant terms in the model's ice dynamics equation elucidates this behavior. The air-ice drag (Figure $7 \mathrm{~b}$ ) is uniform over the region, reflecting widespread northerlies in the NCEP reanalysis. This stress is balanced by ice-ocean drag in the outer thin ice (Figure 7c) in classical free-drift conditions, leading to ice motion at a small angle to the wind at around $2 \%$ of its speed. Ice motion is resisted in stronger thick ice near the coastline, so here the air drag is balanced by the divergence of the internal ice stress (Figure 7d) and the ice slows to a standstill relative to the wind.

\section{Discussion}

[25] Our observations and model results demonstrate that the rapid ice edge retreat of 2-15 May 2001 was primarily driven by strong and persistent northerly winds associated with a low-pressure system that became stationary in the Amundsen Sea. In the outer part of the pack, the ice motion field was locally convergent, implying dynamical thickening on small scales, while, on the broader scale, the southward movement of the ice edge was largely balanced by westward advection of ice nearer to the coast. The spatial variation of ice motion was qualitatively well simulated by the ocean-ice model, giving some confidence that this model was able to simulate the dynamical controls on the retreat event in a realistic manner.

[26] The two models used have enabled us to estimate the thermodynamic contribution to ice volume changes through the retreat event. Near-surface air temperatures remained close to $0^{\circ} \mathrm{C}$ throughout the event, leading to negligible surface melt. However, as a result of these relatively warm air temperatures, the vertical temperature gradient through the ice remained small and almost all of the ocean-ice heat flux was available to drive basal melting. Results from both the kinematic/thermodynamic model and the ocean-ice model indicate basal melt rates, which are a significant fraction of the dynamical contribution to ice thickening in the outer part of the pack. Even in the absence of thermodynamic ice growth and consequent convective stirring of the ocean mixed layer, high values of ocean-ice heat flux were sustained beneath the rapidly retreating ice as a result of mechanical mixing. The reduction in net ice thickness growth rate resulting from the large ocean-ice heat flux may have contributed to the rapid retreat of the ice edge by keeping the outer pack relatively thin and thus easier to deform.

[27] Both the observations and the data from the ocean-ice model reveal contrasting dynamical controls on ice drift in the near-shore and outer regions. In the outer pack, where the ice is relatively thin, the ice is close to a state of free drift. Closer to the shore, by contrast, less of the observed variability in ice motion can be explained by atmospheric 
a)

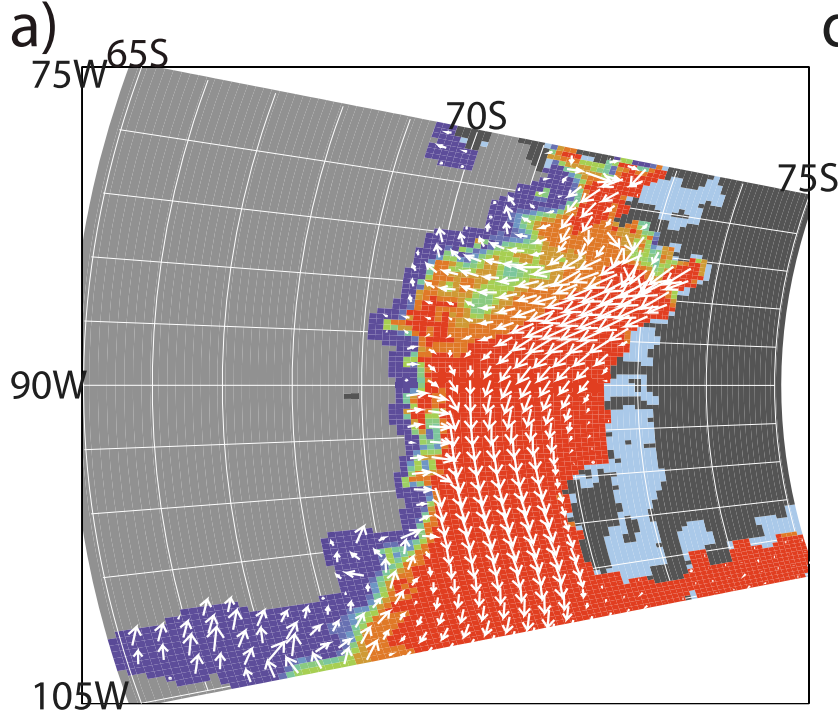

d)

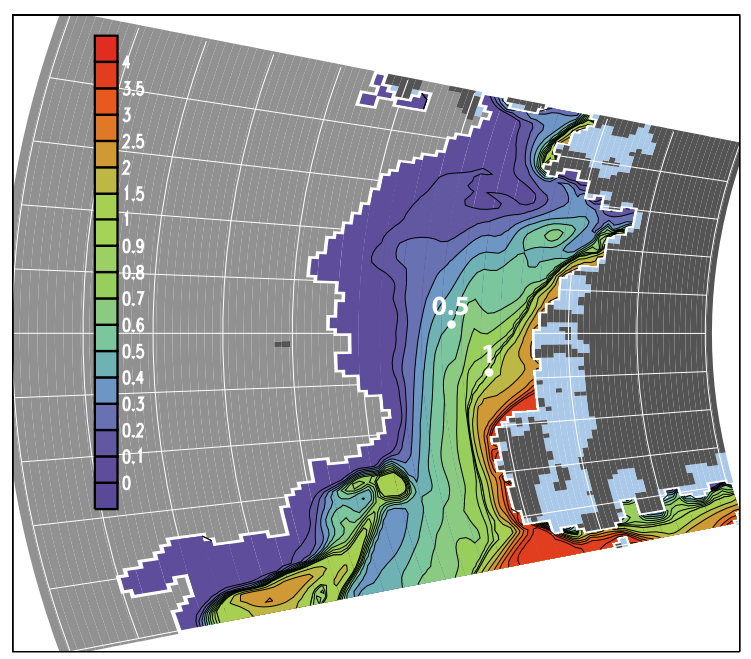

b)

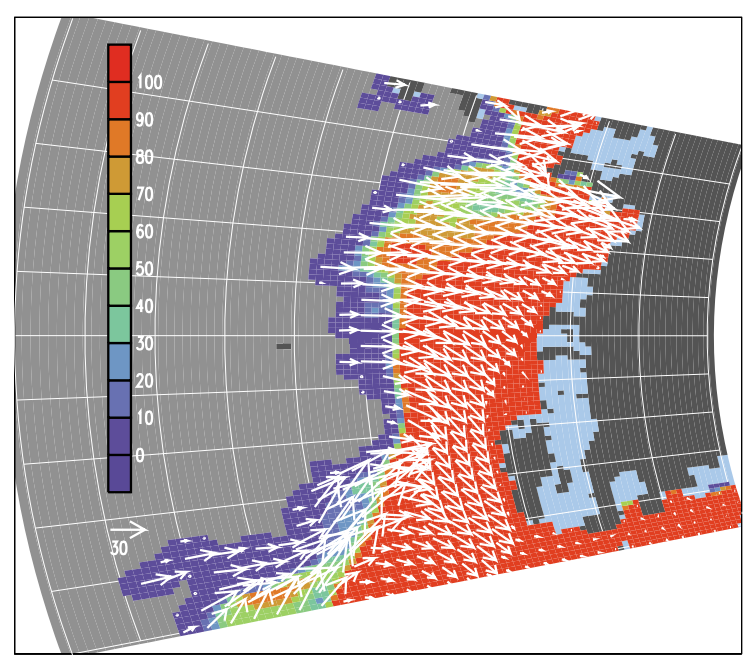

c)

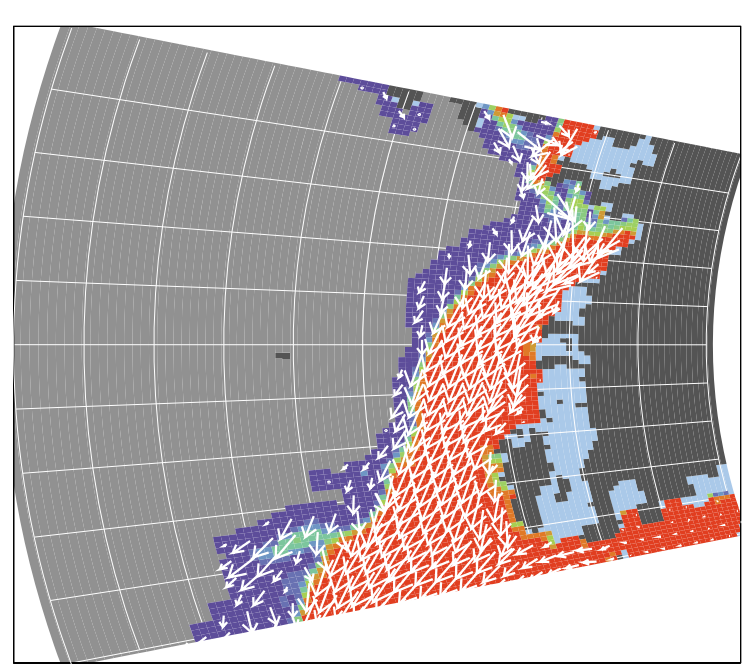

e)

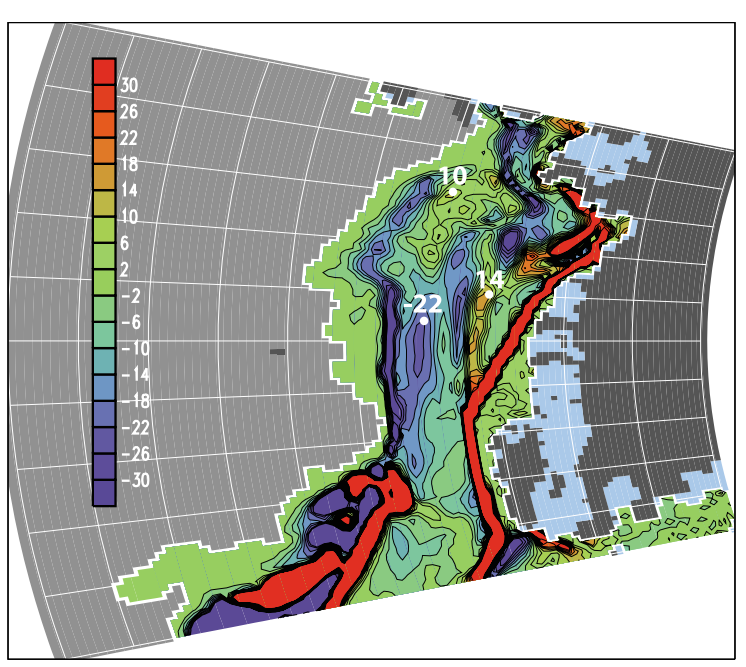

f)

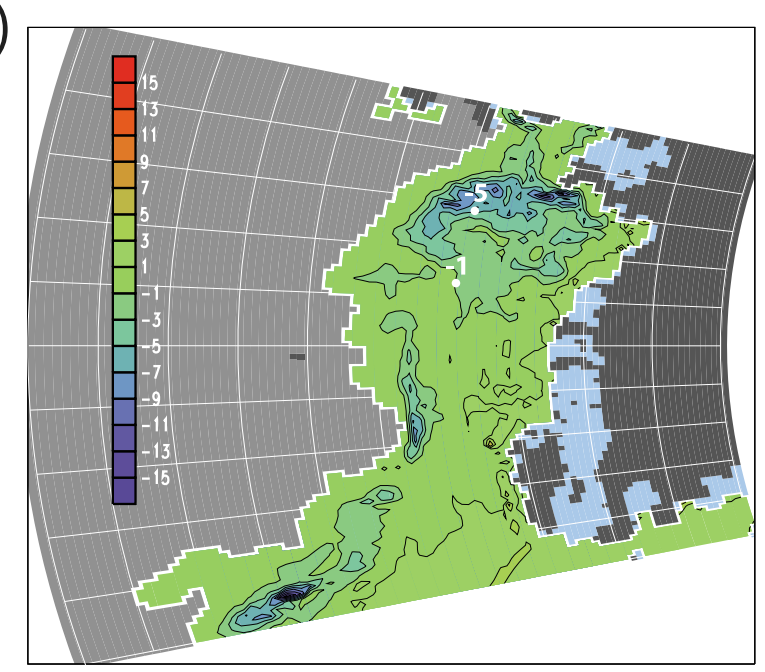

Figure 6. (a-c) Snapshots of model ice concentration and ice motion vectors $\left(\mathrm{cm} \mathrm{s}^{-1}\right.$; shown every third grid point) at 1200 UTC on (a) 2 May 2001, (b) 10 May 2001, (c) 22 May 2001. (d-f) Analysis of the ice model at 1200 UTC on 10 May 2001: (d) ice thickness (m; note break in contour scale), (e) change in ice thickness $\left(\mathrm{m} \mathrm{a}^{-1}\right)$ due to dynamic processes (ridging, rafting, etc.), (f) change in ice thickness $\left(\mathrm{m} \mathrm{a}^{-1}\right)$ due to thermodynamic processes, almost exclusively basal melting (note different scale). 
a)

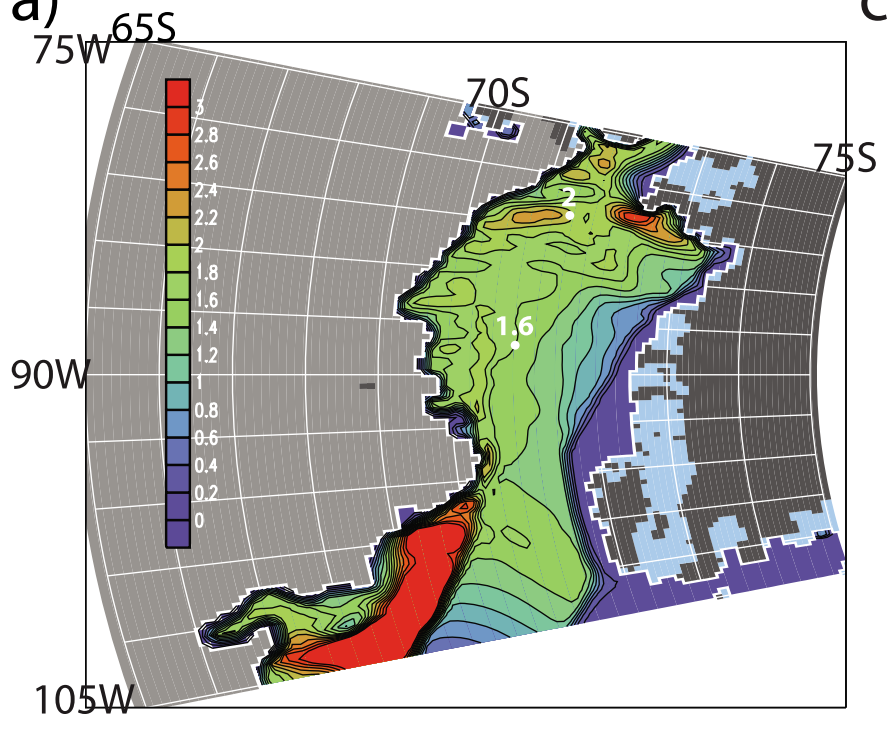

c)

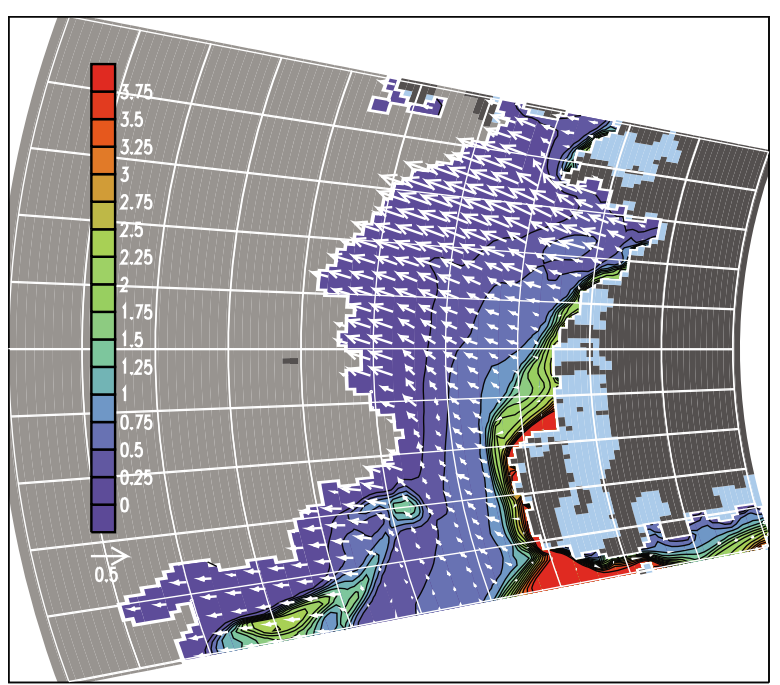

b)

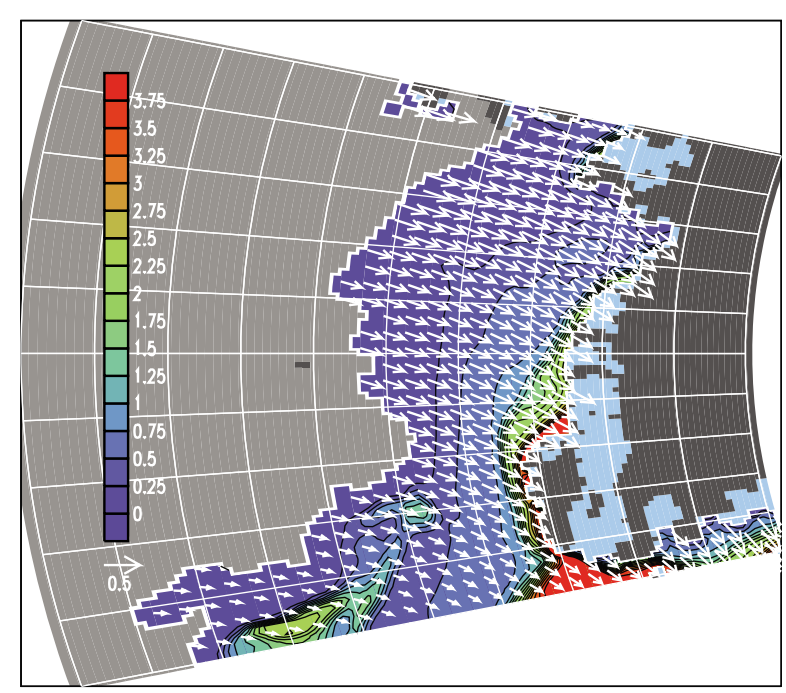

d)

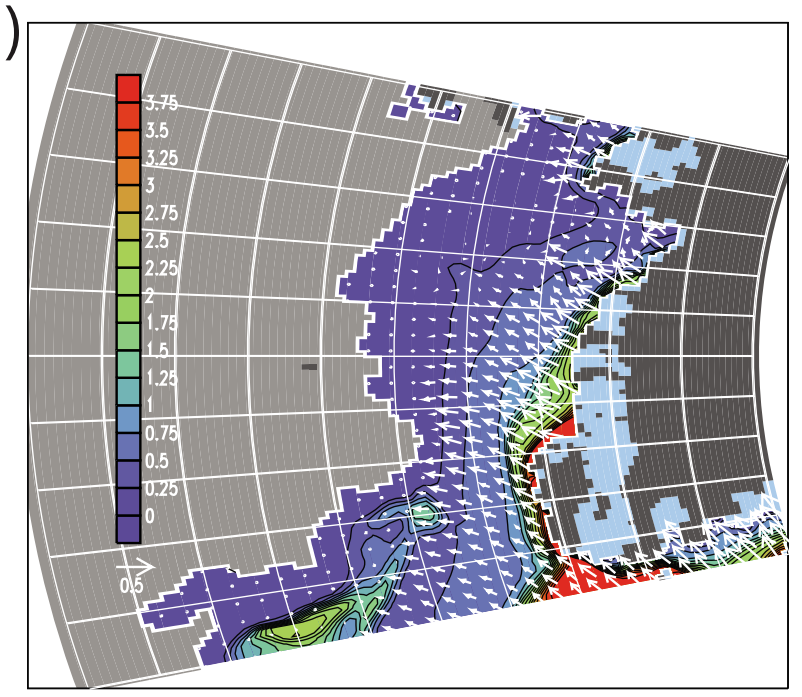

Figure 7. Snapshots of ice model dynamics at 1200 UTC on 10 May 2001. (a) Ratio between ice speed and wind speed $(\%)$. (b-d) Vectors of air-ice drag, ice-ocean drag, and divergence of internal ice stress, respectively $\left(\mathrm{N} \mathrm{m}^{-2}\right.$; shown every third grid point) overlain on ice thickness $(\mathrm{m})$.

forcing. Also, inertial motions are weaker than in the outer region. This contrasting behavior between the outer and inner pack suggests that internal ice stresses become significant in the inner region. Model diagnostics are consistent with this hypothesis. Heil et al. [2009] observed contrasting ice dynamics on and off the continental shelf of East Antarctica during the austral spring of 2003. The contrast in their case arose from increased tidal forcing in the shallower waters over the continental shelf. The bathymetry of this part of the Bellingshausen Sea continental shelf is poorly observed, and consequently, little is known about the spatial variability of tidal forcing in the region. Given the lack of clear tidal signals in our data, we believe that contrasting ice conditions (thicker, more compact ice nearer the coast) were the main contributor to contrasting ice dynamics across our study area.

[28] The anomalous atmospheric circulation that forced the May 2001 retreat event was similar to that which drove a comparable ice edge retreat at $70^{\circ} \mathrm{W}$ during September to October 2001 [Massom et al., 2006]. Like the May 2001 retreat, this later event was also forced by a synoptic scale cyclone that became quasi-stationary to the west of the Antarctic Peninsula as a result of blocking in the South Atlantic sector. Such blocking was anomalously strong and persistent during the winter of 2001 and the following summer [Turner et al., 2003]. However, there are significant differences between the events. While ice thickening (on the broader scale) appears to have been relatively modest during the May 2001 event, Massom et al. [2006] report rafted ice of more than $10 \mathrm{~m}$ thickness over a wide area toward the end of the September to October 2001 event. The higher initial ice thickness in September (0.5-1.5 m first year ice) compared with May (20 cm consolidated pancake ice) will have contributed to the greater thickening observed in the later event. However, differences in large-scale ice drift are 
probably also important. The September to October 2001 event took place in the Marguerite Bay region, where the configuration of the coastline may restrict export of ice to the southwest. The ice edge retreat in this later event would then have had to be balanced by thickening and melt.

[29] The May 2001 event appears to have been exceptional in the context of the long-term sea ice record for this sector of the Antarctic. The maximum 2 week ice retreat at $90^{\circ} \mathrm{W}$ during May, determined from the weekly sea ice edge data set for 1979-1994 produced by Harangozo [2004], is only $200 \mathrm{~km}$, compared to the $250 \mathrm{~km}$ observed in May 2001. Furthermore, 2 week retreat of $100 \mathrm{~km}$ or greater was only observed over six 2 week periods $(9 \%$ of the total) in May from 1979 to 1994. As noted above, regional atmospheric circulation was highly anomalous during 2001, so retreat events as large as those observed in May 2001 and September to October 2001 are likely to be a rare occurrence, although the frequency with which such events are observed may increase as a result of changed atmospheric circulation [Turner et al., 2009]. Smaller retreats are, however, quite common [Harangozo, 1997, 2004]. The dynamics of such smaller events are likely to be similar to those observed in the May 2001 event. Successful replication of this event using the ocean-ice model gives us some confidence that models with sufficient resolution should be able to capture typical Bellingshausen Sea ice retreat events and hence, by extension, should be able to reproduce the annual growth of sea ice in this sector in a realistic manner.

[30] Acknowledgments. We thank the Alfred Wegener Institute and the officers and crew of the research vessel Polarstern for supporting the buoy deployments. The SVPBs were funded by the UK Met Office, and we thank David Meldrum (Scottish Association for Marine Science) for making them available to us. We thank Stephen Harangozo for providing climatological ice edge data and Keith Nicholls for helping us to interpret the spectra displayed in Figure 2. This study is a contribution to the British Antarctic Survey's programme "Polar Science for Planet Earth" and was supported by the U.K. Natural Environment Research Council.

\section{References}

Banks, C. J., M. A. Brandon, and P. H. Garthwaite (2006), Measurement of sea-ice draft using upward-looking ADCP on an autonomous underwater vehicle, Ann. Glaciol., 44, 211-216.

Bleck, R., C. Rooth, D. Hu, and L. T. Smith (1992), Salinity-driven thermocline transients in a wind- and thermohaline-forced isopycnic coordinate model of the North Atlantic, J. Phys. Oceanogr., 22, 1486-1505.

Comiso, J. C. (1999), Bootstrap sea ice concentrations from NIMBUS-7 SMMR and DMSP SSM/I, May 2001, Digital Media, Natl. Snow and Ice Data Center, Boulder, Colo.

Doble, M. J., and P. Wadhams (2006), Dynamical contrasts between pancake and pack ice investigated with a drifting buoy array, J. Geophys. Res., 111, C11S24, doi:10.1029/2005JC003320.

Doble, M. J., M. D. Coon, and P. Wadhams (2003), Pancake ice formation in the Weddell Sea, J. Geophys. Res., 108(C7), 3209, doi:10.1029/ 2002JC001373.

Emery, W. J., and R. E. Thompson (1998), Data Analysis Methods in Physical Oceanography, Oxford, Pergamon.

Emery, W. J., C. W. Fowler, and J. A. Maslanik (1997), Satellite-derived maps of Arctic and Antarctic sea ice motion: 1988 to 1994, Geophys. Res. Lett., 24(8), 897-900, doi:10.1029/97GL00755.

Haas, C. (1998), Evaluation of ship-based electromagnetic-inductive thickness measurements of summer sea-ice in the Bellingshausen and Amundsen seas, Antarctica, Cold Reg. Sci. Technol., 27, 1-16.

Harangozo, S. A. (1997), Atmospheric meridional circulation impacts on contrasting winter sea ice extent in two years in the Pacific sector of the Southern Ocean, Tellus, Ser A, 49, 388-400.

Harangozo, S. A. (2004), The impact of winter ice retreat on antarctic winter sea-ice extent and links to the atmospheric meridional circulation, Int. J. Climatol., 24, 1023-1044.
Heil, P., R. A. Massom, I. Allison, A. P. Worby, and V. I. Lytle (2009), Role of off-shelf to on-shelf transitions for East Antarctic sea ice dynamics during spring 2003, J. Geophys. Res., 114, C09010, doi:10.1029/ 2008JC004837.

Holland, P. R., A. Jenkins, and D. M. Holland (2010), Ice and ocean processes in the Bellingshausen Sea, Antarctica, J. Geophys. Res., 115, C05020, doi:10.1029/2008JC005219.

Hunke, E. C., and W. H. Lipscomb (2006), CICE: The Los Alamos Sea Ice Model Documentation and Software User's Manual, Los Alamos Natl. Laboratory, Los Alamos, N.M. (Available at http://climate.lanl.gov/ Models/CICE/)

King, J. C. (1994), Recent climate variability in the vicinity of the Antarctic Peninsula, Int. J. Climatol., 14, 357-369.

King, J. C. (2003), Validation of ECMWF sea level pressure analyses over the Bellingshausen Sea, Antarctica, Weather Forecast., 18, 536-540.

Lipscomb, W. H., E. C. Hunke, W. Maslowski, and J. Jakacki (2007), Ridging, strength, and stability in high-resolution sea ice models, J. Geophys. Res., 112, C03S91, doi:10.1029/2005JC003355.

Martinson, D. G., S. E. Stammerjohn, R. A. Iannuzzi, R. C. Smith, and M. Vernet (2008), Western Antarctic Peninsula physical oceanography and spatio-temporal variability, Deep Sea Res., Part II, 55, 1964-1987.

Massom, R. A., et al. (2006), Extreme anomalous atmospheric circulation in the West Antarctic Peninsula region in Austral Spring and Summer 2001/02, and its profound impact on sea ice and biota, J. Clim., 19, 3544-3571.

Massom, R. A., S. E. Stammerjohn, W. Lefebvre, S. A. Harangozo, N. Adams, T. A. Scambos, M. J. Pook, and C. Fowler (2008), West Antarctic Peninsula sea ice in 2005: Extreme ice compaction and ice edge retreat due to strong anomaly with respect to climate, J. Geophys. Res., 113, C02S20, doi:10.1029/2007JC004239.

Maykut, G. A., and M. G. McPhee (1995), Solar heating of the Arctic mixed layer, J. Geophys. Res., 110(C12), 24,691-24,703, doi:10.1029/ 95JC02554.

Meredith, M. P., and J. C. King (2005), Rapid climate change in the ocean west of the Antarctic Peninsula during the second half of the 20th century, Geophys. Res. Lett., 32, L19604, doi:10.1029/2005GL024042.

Olbers, D., V. Gouretski, G. Seiss, and J. Schröter (1992), Hydrographic Atlas of the Southern Ocean, Alfred Wegener Inst., Bremerhaven, Germany. (Available at http://gcmd.nasa.gov/records/GCMD_AWI-SODB.html)

Orr, A., D. Cresswell, G. J. Marshall, J. C. R. Hunt, J. Sommeria, C. G. Wang, and M. Light (2004), A 'low-level' explanation for the recent large warming trend over the western Antarctic Peninsula involving blocked winds and changes in zonal circulation, Geophys. Res. Lett., 31, L06204, doi:10.1029/ 2003GL019160.

Rothrock, D. A. (1975), The energetics of the plastic deformation of pack ice by ridging, J. Geophys. Res., 80(33), 4514-4519, doi:10.1029/ JC080i033p04514.

Thorndike, A. S., D. A. Rothrock, G. A. Maykut, and R. Colony (1975), The thickness distribution of sea ice, J. Geophys. Res., 80(33), 4501-4513, doi:10.1029/JC080i033p04501.

Turner, J., S. A. Harangozo, J. C. King, W. M. Connolley, T. A. LachlanCope, and G. J. Marshall (2003), An exceptional winter sea-ice retreat/ advance in the Bellingshausen Sea, Antarctica, Atmos. Ocean, 41, $171-185$.

Turner, J., S. R. Colwell, G. J. Marshall, T. A. Lachlan-Cope, A. M. Carleton, P. D. Jones, V. Lagun, P. A. Reid, and S. Iagovkina (2005), Antarctic climate change during the last 50 years, Int. J. Climatol., 25, 279-294.

Turner, J., J. C. Comiso, G. J. Marshall, T. A. Lachlan-Cope, T. Bracegirdle, T. Maksym, M. P. Meredith, Z. M. Wang, and A. Orr (2009), Nonannular atmospheric circulation change induced by stratospheric ozone depletion and its role in the recent increase of Antarctic sea ice extent, Geophys. Res. Lett., 36, L08502, doi:10.1029/2009GL037524.

Vihma, T., J. Launianen, and J. Uotila (1996), Weddell Sea ice drift: Kinematics and wind forcing, J. Geophys. Res., 101(C8), 18,279-18,296, doi:10.1029/96JC01441.

Worby, A. P., M. O. Jeffries, W. F. Weeks, K. Morris, and R. Jana (1996), The thickness distribution of sea ice and snow cover during late winter in the Bellingshausen and Amundsen Seas, Antarctica, J. Geophys. Res., 101(C12), 28,441-28,455, doi:10.1029/96JC02737.

Zwally, H. J., J. C. Comiso, C. L. Parkinson, D. J. Cavalieri, and P. Gloersen (2002), Variability of Antarctic sea ice 1979-1998, J. Geophys. Res., 107(C5), 3041, doi:10.1029/2000JC000733.

M. J. Doble, Laboratoire d'Océanographie de Villefranche, UPMC Univ Paris 06, Villefranche/mer, France.

P. R. Holland and J. C. King, British Antarctic Survey, High Cross, Madingley Rd., Cambridge, CB3 0ET, UK. (jcki@bas.ac.uk) 